\title{
Governança em cenários de escassez hídrica: uma análise comparada dos Complexos Hidropolíticos da África Meridional e da Bacia do Rio Jordão
}

\author{
Fábio Albergaria de Queiroz ${ }^{*}$ \\ James Augusto Pires Tiburcio** \\ * Instituto de Relações Internacionais da Universidade de Brasília, Brasil; fabioaq@hotmail.com \\ ** Universidade de Brasília, Brasil.
}

\begin{abstract}
Resumo
A água doce é um recurso escasso e, sem dúvida, uma das características mais marcantes nas últimas décadas tem sido a crescente percepção de problemas relacionados à sua finitude como um componente importante no jogo de poder regional. Esta situação ajuda a explicar porque a gestão de recursos hídricos encontra-se, muitas vezes, vinculada a preocupações de ordem política, econômica, social, ambiental e, até mesmo, militar. Mas, em que intensidade? Em busca de respostas, são analisadas duas sub-regiões com quadro de estresse hídrico: a África Meridional e a Bacia do rio Jordão. A fim de verificar o papel desempenhado pelos mecanismos de governança na acomodação dos interesses dos países que integram estes espaços, o artigo empregou o modelo analítico dos Complexos Hidropolíticos para demonstrar, como resultado, uma tendência à cooperação na África Meridional em decorrência da bem sucedida institucionalização de instrumentos de gestão capazes de minimizar o potencial de conflitos. Já na Bacia do Jordão, as disputas pelo controle dos recursos hídricos tem sido determinantes na manutenção de um quadro prevalecente de tensão entre os países ribeirinhos.
\end{abstract}

Palavras-chave: África Meridional; Bacia do Jordão; complexos hidropolíticos; escassez hídrica; interdependência hidrológica

\begin{abstract}
Water is an increasingly scarce resource. One of the most noteworthy discursive features of the last decades has been a growing awareness of water-related issues as a critically important component for regional stability. This situation helps to explain why, in many cases, water management involves political, economic, social, environmental and even military issues. But, in what intensity? This article analyzes the cases of Southern Africa and the Jordan River Basin due to their prevailing condition of water scarcity. In order to verify the role developed by the mechanisms of governance in accommodating the interests of the riparian states, the Hydropolitical Complexes Theory was applied. Inferences demonstrated a trend towards cooperation in Southern Africa that is due to the successful institutionalization of management mechanisms capable of minimizing potential for conflicts. On the other hand, in the Jordan Basin, the struggle to control water resources has been a significant factor in sustaining tension among riparian countries.
\end{abstract}

Keywords: hydrological interdependence; hydropolitical complexes; Jordan River Basin; Southern Africa; water scarcity 


\section{Introdução}

O planeta dispõe de aproximadamente 1,4 bilhão de $\mathrm{km}^{3}$ de água. Contudo, quase todo essa imensidão, cerca de $97,5 \%$, é salgada. Dos $2,53 \%$ de água doce tecnicamente disponível, uma quantia ínfima encontra-se acessível ao uso humano (apenas $1 / 3$ deste montante) e, ainda assim, desigualmente distribuída ao longo de um emaranhado de lagos, rios, zonas úmidas e aquíferos que, em muitos casos, ignoram as fronteiras nacionais, condição essa que, ao estabelecer uma inegável relação de interdependência, faz dos recursos hídricos uma importante referência nas relações daqueles que os compartilham (Clarke \& King, 2005, p. 20; United Nations Institute for Training and Research [UNITAR], 2015, p. 5).

Mais especificamente, dados da Organização das Nações Unidas para a Educação, a Ciência e a Cultura (UNESCO), entidade responsável pelo Programa Mundial de Avaliação Hídrica, dão conta da existência de 263 bacias transfronteiriças sendo que, delas, treze são compartilhadas por cinco ou mais países (Organização das Nações Unidas para a Educação, a Ciência e a Cultura [UNESCO], 2003, p. 303). Essa notável condição comunal também é observada em relação aos aquíferos, que, para quase $1 / 4$ da população mundial, representam a única fonte de água potável. ${ }^{[1]}$

Nesse complexo cenário, evidências empíricas logo demonstraram que a água tende a atuar como um poderoso elemento conectivo conforme o grau de dependência de cada um destes atores em relação aos sistemas hídricos compartilhados utilizados para o atendimento de suas múltiplas demandas: da dessedentação à produção energética, da irrigação ao consumo industrial. Consequentemente, a qualidade e a disponibilidade desses recursos comunais serão diretamente impactadas pela forma como seus usos são geridos e as eventuais externalidades resultantes controladas ${ }^{[2]}$ (Le Prestre, 2000, pp. 440-43; UNITAR, 2015, p. 9).

Soma-se a esse quadro estimativas capazes de lhe conferir dramaticidade ainda maior, como a previsão de que por volta de 2050 quase metade da população mundial viverá em áreas com escassez crônica de água ${ }^{[3]}$ ou onde o sistema hídrico esteja seriamente ameaçado por fatores como mudanças climáticas e crescimento demo-

1. Inventário produzido pela UNESCO em 2008, o Mapa Mundial de Aquíferos Transfronteiriços, aponta a existência de 273 aquíferos partilhados por pelo menos dois países. Eles estão assim distribuídos: 68 no continente americano, 38 na África, 65 no Leste Europeu, 90 na Europa Ocidental e 12 na Ásia (Fonte: $<$ http://www.whymap.org >).

2. Externalidades são impactos gerados pelas ações de um determinado agente sobre o bem-estar de terceiros sem que estes tenham qualquer controle ou participação nestas ações. Quando as externalidades geram custos diz-se que são negativas e, contrariamente, quando geram benefícios, diz-se que são positivas.

3. A chamada escassez de primeira ordem (ou de recursos naturais) refere-se, aqui, à disponibilidade de água. A partir desta tipologia tem-se um quadro de: 1) pré-estresse hídrico quando a disponibilidade per capita varia entre $1.600-2.000 \mathrm{~m}^{3} / \mathrm{ano} ; 2$ ) estresse hídrico (water shortage) entre 1.000 e $1.600 \mathrm{~m}^{3} / \mathrm{ano}$ 3) escassez crônica de água (water scarcity) quando este montante é de menos de $500 \mathrm{~m}^{3} /$ ano per capita. Intrinsecamente ligada a estes cenários temos também a escassez de segunda ordem (de recursos sociais) que, em linhas gerais, refere-se à falta de habilidade e/ou de capacidade de adaptação dos atores sociais para lidar com as mudanças impostas por um cenário de crescente escassez hídrica. 
gráfico desordenado (UNITAR, 2015, p. 5) ${ }^{[4]}$. Por isso, a validade do alerta feito por Elhance (1999, p. 230) de que:

in a situation of growing water scarcity, the highly complex and multidimensional interdependences created by transboundary water resources constrain states from asserting their sovereignty and unilaterally pursuing the goals of national security, economic development and social welfare.

Esse quadro, ainda que prospectivo, nos leva a refletir acerca de suas possíveis implicações em temas fundamentais da agenda internacional contemporânea como: a soberania sobre os recursos naturais, segurança regional, acesso e utilização da água, proteção do meio ambiente, desenvolvimento sustentável, conflito e cooperação, entre outros.

O capítulo 18 da Agenda 21 ${ }^{[5]}$, documento adotado na Conferência das Nações Unidas sobre Meio Ambiente e Desenvolvimento, nos lembra, por exemplo, que "a escassez generalizada, a destruição gradual e o agravamento da poluição dos recursos hídricos em muitas regiões do mundo, ao lado da implantação progressiva de atividades incompatíveis, exigem o planejamento e manejo integrados desses recursos” e, em uma perspectiva de cooperação entre os Estados no marco dos acordos e arranjos pertinentes, reconhece que "os recursos hídricos transfronteiriços e seu uso são de grande importância para os Estados ribeirinhos".

Da mesma forma, os Estados que subscreveram a Declaração do Milênio das Na-

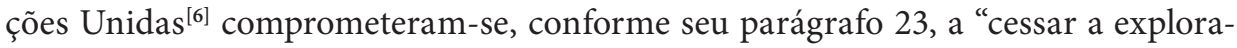
ção insustentável dos recursos hídricos, formulando estratégias de gestão nos planos regional, nacional e local, capazes de promover um acesso equitativo e um abastecimento adequado".

4. Estudo publicado em março de 2015 pela UNESCO - (Relatório Mundial das Nações Unidas sobre o Desenvolvimento de Recursos Hídricos - Água para um Mundo Sustentável) — alerta que cerca de 748 milhões de pessoas não têm acesso a fontes de água potável e que $20 \%$ dos aquíferos mundiais já são explorados excessivamente, o que pode gerar graves consequências como a erosão do solo e a invasão de água salgada nesses reservatórios. O relatório ainda prevê que as reservas hídricas do mundo podem encolher $40 \%$ até 2030 e que em 2050, a agricultura e a indústria de alimentos vão precisar aumentar em $400 \%$ sua demanda por água. Somam-se a este quadro pessimista as estimativas de que com um aumento médio na temperatura do planeta na ordem de $2^{\circ} \mathrm{C}$ (isso no cenário mais otimista conforme avaliação do painel da ONU sobre Mudanças Climáticas), a escassez de água fatalmente seria triplicada em áreas extremamente vulneráveis como o Norte da África, Oriente Médio e Ásia central. Áreas densamente povoadas de países desenvolvidos que vivem situações de escassez crônica, como o sudoeste dos EUA e sudeste da Austrália, também seriam severamente impactadas.

5. Agenda 21. Proteção da Qualidade e do Abastecimento dos Recursos Hídricos: aplicação de critérios integrados no desenvolvimento, manejo e uso dos recursos hídricos. Aprovada pela Resolução da Assembleia Geral n. ${ }^{\circ}$ 47/190, de 22 de dezembro de 1992.

6. Resolução da Assembleia Geral n. ${ }^{\circ}$ 55/L.2, de 9 de setembro de 2000. 
Diante dessas colocações preliminares, um olhar sobre os cenários descritos pela hidropolítica internacional - termo doravante utilizado para designar as dinâmicas multissetoriais, cooperativas e/ou conflitivas, oriundas das relações de interdependência que se estabelecem entre aqueles atores (estatais e não estatais) que, em alguma medida, impactam e/ou são impactados pelos usos de recursos hídricos comuns (Queiroz, 2012) - revela-nos importantes aspectos que requerem algumas considerações, ainda que breves.

Na medida em que a qualidade da água se degrada e/ou a quantidade disponível tem que atender a demandas crescentes e variadas, uma competição feroz entre os usos e usuários da água tem o potencial de intensificar-se exponencialmente. Esta situação é preocupante, sobretudo, naquelas regiões que concentram os pontos mais críticos de estresse hídrico ou escassez absoluta de água como são os casos do Oriente Médio, África Subsaariana e Sudeste Asiático. A este respeito, é consensual o fato de que os acordos internacionais devem ser mais eficazes na definição de mecanismos de resolução de conflitos envolvendo recursos hídricos (UNITAR, 2015). ${ }^{[7]}$

Por conseguinte, nesse panorama em que o compartilhamento de recursos hídricos apresenta o potencial de ensejar relações de alta complexidade na medida em que as ações de um ator podem comprometer os interesses de seus vizinhos, geralmente é possível identificar-se com nitidez um quadro, aqui fazendo uso da terminologia cunhada por Elhance (1999, p. 13), de interdependência hidrológica. Em tal situação, o conceito de vulnerabilidade descrito por Keohane e Nye (1989, p. 12) como "a capacidade de reação de um Estado, considerando-se a disponibilidade e a dispendiosidade das alternativas que os atores possuem" torna-se um elemento igualmente importante nas relações internacionais daqueles que compartilham o uso e a gestão de recursos hídricos.

Afinal, aponta Le Prestre (2000, p. 442), a água pode aguçar situações de tensão conforme: 1) o grau de vulnerabilidade e dependência de cada país com relação aos seus múltiplos usos; 2) o número de atores que reivindicam o acesso a ela; 3 ) os recursos de poder de que dispõem estes atores; 4) a existência de produtos substitutivos (inexistentes no presente) ou, até mesmo; 5) o caráter simbólico que assume este recurso em termos políticos, culturais e de identidade. ${ }^{[8]}$

7. A história dos tratados envolvendo recursos hídricos remonta a 2500 a. C., quando as cidades sumérias de Lagash e Umma celebraram acordo encerrando uma disputa sobre a utilização das águas do rio Tigre. Segundo a Organização das Nações Unidas para a Alimentação e a Agricultura (FAO), mais de 3.600 tratados relacionados com os recursos hídricos foram elaborados desde 805 d. C., principalmente para tratar da navegação e demarcação de fronteiras. No entanto, o foco da negociação e da elaboração de tratados no século passado deslocou-se das questões acima mencionadas para o uso, desenvolvimento, proteção e conservação dos recursos hídricos (Fonte: <http://www.un.org/waterforlifedecade/transboundary_waters.html.>)

8. Sobre a predominante orientação estatocêntrica dos estudos em hidropolítica, Marton e Szâlka (2017) fazem uma crítica a esta vertente devido, segundo os autores, à demasiada ênfase atribuída a uma representação binária e distorcida da realidade empírica, como se a hidropolítica fosse, ao fim, nada mais do que o resultado de "upstream-downstream state relations", perspectiva esta que "often serves to empower states - as the owners of waters - above other actors" (p. 1). Em resposta, eles propõem a verticalização dos estudos sobre o tema por ser esta alternativa mais inclusiva e capaz de promover uma governança mais justa. 
Portanto, diante destas ponderações, e consoante com a natureza holística e multissetorial da hidropolítica, para verificar a eficácia dos instrumentos de gestão de recursos hídricos em cenários de escassez, esta proposta investigativa parte de uma perspectiva mais ampla e inclusiva de governança (enquanto processo de acomodação de consensos e, também, de conflitos e divergências) considerando-a, para tanto, como sendo:

a multi-layered, multi-scale and multi-sector ensemble characterized by a combination of hierarchical structures, participatory dynamics, associative action and market mechanisms based on a culture of dialogue, negotiation, active citizenship, subsidiarity and institutional strengthening (Castro, 2007, p. 103). ${ }^{[9]}$

Logo, levando-se em conta a inegável importância da governança para a adequada gestão de um bem comunal e escasso - a água - eis as perguntas para os quais este artigo busca respostas: em que medida os diversos usos de recursos hídricos se inter-relacionam com as dinâmicas multissetoriais daqueles atores que os compartilham? E, ainda, ao favorecer aspectos conflitantes e/ou arranjos cooperativos entre os atores ribeirinhos, como os desdobramentos resultantes destas interações repercutem na construção de mecanismos de governança?

\section{Metodologia, níveis e unidades de análise}

Apesar dos níveis de análise, em sua acepção mais generalista, servirem mais como referências ontológicas, onde fatos ocorrem, do que como, propriamente, fontes de respostas para os porquês de tais fatos acontecerem (Buzan, Wæver \& De Wilde, 1998, pp. 5-6), cabe destacar sua reconhecida importância epistemológica na medida em que proporcionam ao estudo coerência analítica, sobretudo, quando o método investigativo utilizado é o comparado.

Nesse sentido, para maximizar a instrumentalização eficiente do método, e, por conseguinte, a validação dos resultados esperados, cumpre seguir alguns passos implícitos neste processo de identificação tanto dos elementos comuns aos diferentes casos como daqueles singulares, que por vezes não se repetem: 1) a seleção dos fenômenos a serem observados e; 2) a definição dos elementos a serem comparados.

Considerando, então, a contiguidade territorial como variável de controle ${ }^{[10]} \mathrm{e}$, consequentemente, o nível de análise como sendo o subsistêmico regional temos,

9. Rotulado pela literatura especializada como gestão colaborativa ou participativa da água (Plummer et al., 2012; Van Buuren, 2013), a natureza policêntrica desta abordagem baseada na maior participação das partes interessadas incentiva esforços experimentais em vários níveis, o que pode conduzir ao desenvolvimento de métodos para avaliar de forma mais precisa os custos e benefícios de estratégias específicas adotadas em determinadas situações, e, logo, a possibilidade de compará-los com os resultados obtidos em outras. Esse modelo se aproxima do que está sendo chamado de modo de governança experimentalista por cientistas políticos como Charles F. Sabel e Robert O. Keohane.

10. Uma variável que é mantida constante para avaliar ou esclarecer a relação entre duas outras variáveis, nesse caso, a eficácia dos mecanismos de governança (variável dependente) e a escassez de água (variável independente). 
pois, no modelo conceitual dos Complexos Hidropolíticos nossas unidades referenciais por serem ontologicamente equiparáveis (isto é, áreas geograficamente contíguas em que os atores que as compõem compartilham uma profunda interdependência hidrológica). Por conseguinte, para manter a mesma coerência comparativa, no âmbito dos Complexos Hidropolíticos serão analisadas, como subunidades, algumas de suas principais bacias hidrográficas.

Por sua vez, a necessária conexão entre a metodologia e o quadro teórico - já que sua capacidade explicativa se fragiliza na ausência de um corpo teórico que lhe confira sentido na análise dos dados - referenda a escolha do método comparado para balizar este estudo, pois, a comparação nos permitirá descobrir regularidades, deslocamentos e transformações, semelhanças e diferenças na busca de explicações generalizáveis a partir da análise dos casos previamente selecionados, esforço no qual nos debruçaremos nas próximas páginas.

Para tanto, utilizaremos uma combinação de técnicas comparativas denominada por Skocpol e Somers (1980) como ciclo de investigação, que, basicamente, consiste no uso de múltiplas estratégias de abordagem, neste caso, 1) o controle de hipóteses que consiste no estudo sistemático das covariações identificadas nos estudos de caso; 2) a demonstração paralela em que há a aplicação no universo de pesquisa de um conceito, conjunto de conceitos e/ou um modelo concreto - em nosso caso o modelo descritivo dos Complexos Hidropolíticos - evidenciando, assim, sua validade explicativa; e, por fim, mas não menos importante, 3) o contraste de contextos por meio do qual buscaremos colocar em evidência as diferenças recíprocas existentes entre os casos selecionados.

Tecidas as devidas considerações de ordem metodológica cumpre, então, ressaltar que foi tendo como ponto de partida este mesmo referencial preceptivo (interdependência hidrológica) que Michael Schulz — buscando evidências sobre possíveis conexões entre as dinâmicas hidropolíticas originadas no contexto específico da bacia dos rios Tigre e Eufrates e a agenda de segurança de Iraque, Turquia e Síria - formulou, em 1995, o conceito de Complexo Hidropolítico de Segurança (CHS), uma das variantes do referencial teórico utilizado na busca de respostas para as perguntas ora levantadas.

A ideia de um conceito descritivo aplicável aos casos em que a hidropolítica atua como uma variável relevante para o entendimento das dinâmicas regionais foi concebida a partir da observação das externalidades geradas pela construção de barragens, controle do fluxo de água e geração de energia hidrelétrica nos "rios gêmeos". A partir das inferências obtidas, Schulz sugeriu haver um CHS quando "a set of states that are geographically part owners and technically users of shared rivers start to consider, as a consequence, this water body to be a major national security issue" Schulz (1995, p. 97).

Não obstante sua importância, o conceito dos Complexos Hidropolíticos de Segurança, tal qual proposto, apresentava limitações, dentre as quais, considerar basicamente eventos conflituosos, o que restringia sua capacidade explicativa quando aplicado, por exemplo, em contextos em que prevalecessem arranjos cooperativos. 
Além disso, o modelo desenvolveu-se tendo como foco o compartilhamento de águas superficiais.

Destas ressalvas, surgem alguns pontos importantes para reflexão. Primeiramente, seria possível ter estruturas similares que contemplem uma situação de interdependência hidrológica, mas em um contexto de cooperação? Ou ainda, as dinâmicas originadas a partir do compartilhamento de águas subterrâneas, como os aquíferos, também poderiam ensejar a formação de Complexos?

Levando em conta as citadas limitações do trabalho de Schulz, Allan (2001) e, posteriormente, Turton (2003) aperfeiçoaram o modelo original ao incorporarem a ele novas dimensões, de forma a dotá-lo de maior capacidade explicativa. Para tal, foram introduzidos como variável independente os padrões de amizade/inimizade entre os ribeirinhos e, também, passou-se a conferir maior atenção ao compartilhamento de sistemas hídricos subterrâneos para explicar o papel da hidropolítica em sub-regiões como a África Ocidental e Meridional e o Oriente Médio.

Assim, a partir destes testes empíricos, Allan (2001, 2002) e Turton (2003, 2008) passaram a contemplar, de forma abrangente, a existência do que eles chamaram de Complexos Hidropolíticos naquelas regiões em que "a dependence on shared water systems - both surface and groundwater - is of such a strategic nature that this dependence starts to drive inter-state relations of potential cooperation (amity) and/ or competition (enmity) in a discernable manner" (Turton, 2008, p. 188).

Por conseguinte, os autores também convencionaram que se as relações entre os ribeirinhos tenderem ao fortalecimento dos laços de amizade e da cooperação mútua têm-se, como resultante, o esboço de um Complexo Hidropolítico estável (CH). Por outro lado, se estas dinâmicas indicarem um cenário conflituoso, como no caso envolvendo Turquia, Iraque e Síria, tem-se, tal qual definiu Schulz, a formação de um Complexo Hidropolítico de Segurança (CHS). Portanto, de acordo com esta revisão ontológica, o CHS passou a ser uma variante desse conceito principal, contudo, mantendo a mesma função para a qual fora concebido: mapear espaços marcados por situações de elevada tensão por conta de disputas envolvendo recursos hídricos.

Assim, definidos o referencial metodológico e o nível de análise e determinado o modelo conceitual dos Complexos Hidropolíticos como marco teórico, a partir de sua aplicação buscaremos mapear evidências que demonstrem a grau de vulnerabilidade daqueles que compartilham recursos hídricos em cenários de elevada interdependência hidrológica e, por conseguinte, o papel desempenhado pelos mecanismos de governança na acomodação dos interesses destes atores. Para tanto, escolheu-se como unidades de análise duas sub-regiões notadamente marcadas por quadros de estresse hídrico: os Complexos hidropolíticos da África Meridional e da Bacia do rio Jordão. 

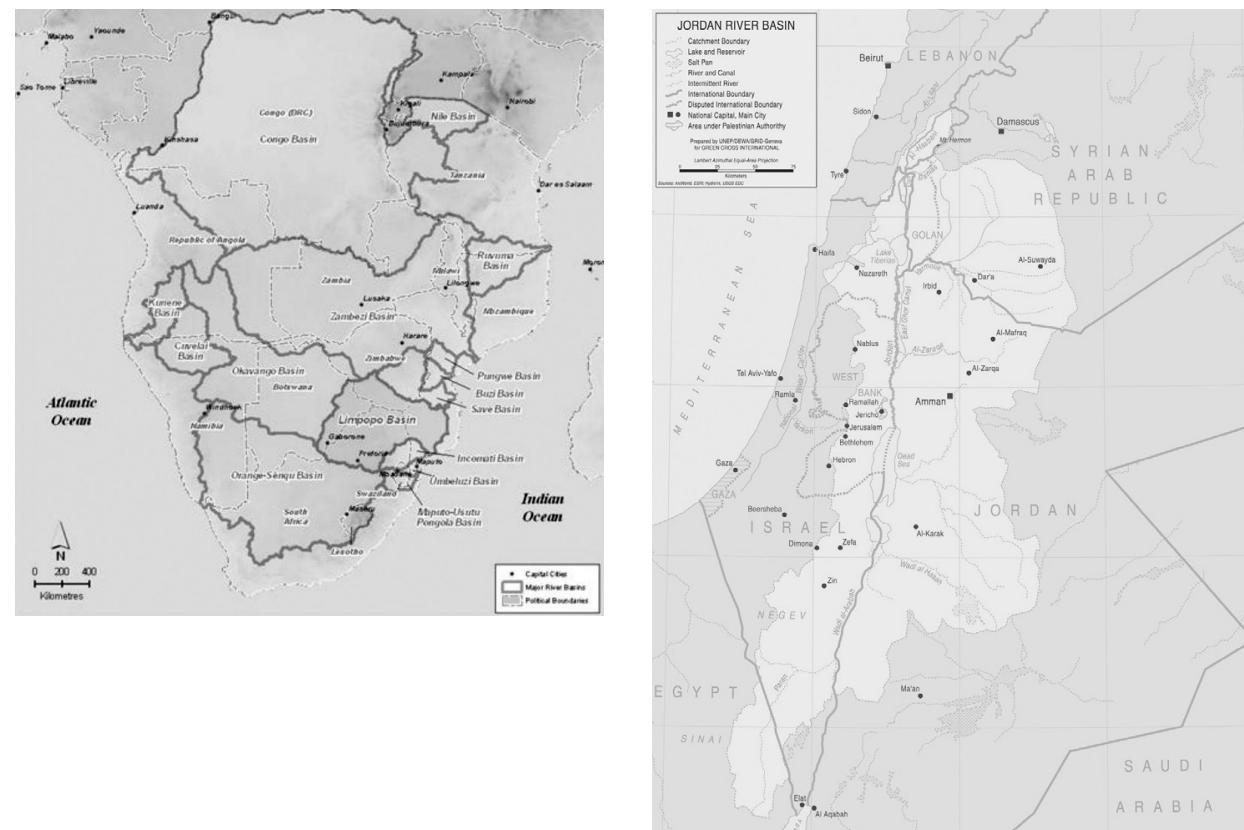

Figura 1. Universo de Análise - Complexos Hidropolíticos da África Meridional e Bacia do Rio Jordão

Fonte: $<$ http://www.orangesenqurak.com/river/Geography/Basins+of+Southern+Africa.aspx $>$;

$<$ http://www.internationalwaterlaw.org/blog/category/water-conflicts/>.

Logo, para cumprir os objetivos propostos, faz-se, doravante, uma apresentação amostral de algumas das principais dinâmicas estruturais e conjunturais definidoras de tais espaços hidropolíticos para, então, analisarmos, comparativamente, a eficácia dos mecanismos de governança vis-à-vis as externalidades resultantes da interdependência hidrológica existente entre os principais atores de ambos Complexos Hidropolíticos.

\section{Complexo Hidropolítico da África Meridional (CHAM)}

A África Meridional, ou Austral ${ }^{[11]}$, conviveu, ao longo de sua história recente, com vários problemas. Primeiramente, o colonialismo e, subsequentemente, a Guerra Fria, já que este espaço figurou como um dos principais cenários das disputas por áreas de influência entre Estados Unidos e a então União Soviética. Somado a esse quadro, o apartheid também desempenhou papel significativo na paisagem geopolítica regional. Mas, com a remoção destes constrangimentos, as dinâmicas endêmicas, próprias dos atores locais, assumiram maior protagonismo e passaram a definir

11. África do Sul, Angola, Botsuana, Comores, Lesoto, Madagascar, Malaui, Ilhas Maurício, Moçambique, Namíbia, Suazilândia, República Democrática do Congo, Zâmbia e Zimbábue. 
a agenda de segurança sub-regional que visivelmente ganhou maior autonomia em relação aos assuntos da agenda sistêmica global (Turton, 2015).

Dentre as manifestações que se sobressaíram destacam-se as relações hidropolíticas, pois, como admoestam Wolf, Yoffe \& Giordano (2003) e Kaniaru (2010), para que a estabilidade político-social e o desenvolvimento econômico sejam condições duradouras na África Meridional, especial atenção deve ser dedicada à gestão das águas transfronteiriças dada sua importância estratégica para os atores que as compartilham. Uma característica notável da hidropolítica da África Austral durante este período foi o fato de que das dezessete bacias hidrográficas mais ameaçadas do mundo, seis delas encontravam-se nos domínios desta sub-região, a saber: Incomati, Kunene, Limpopo, Okavango, Orange e Zambezi (Wolf et al., 2003, pp. 29, 52), situação que, como veremos, já não persiste ${ }^{[12]}$. Assim, ao considerar as peculiaridades características deste espaço, suas intrínsecas conexões com a hidropolítica e os potenciais desdobramentos desta associação nos vários setores que compõem a estrutura organizacional dos atores sub-regionais, notadamente, mas não exclusivamente, os Estados, Turton $(2002,2003,2005,2006,2015)$ reuniu subsídios para fundamentar sua hipótese de que na porção austral do continente estava emergindo um Complexo Hidropolítico ${ }^{[13]}$.

A África meridional - reunindo um grande número de bacias transfronteiriças, pelos menos quinze - depara-se com uma notável taxa de crescimento populacional em um cenário marcado por um quadro predominante de estresse hídrico, uma combinação perigosa capaz de elevar a gestão dos recursos hídricos ao status de assunto de segurança, sobretudo naquelas situações em que prevaleça entre os ribeirinhos a competição pelo acesso à água.

Como há tempos já atestava Turton (2003, p. 31), no caso aludido "water [...] is an important natural resource on which stable economic development is based, forming a fundamental component of the 'physical base' of the state, particularly under conditions of aridity”. Dessa forma, a hidropolítica assume contornos nítidos neste tipo de cenário em que a escassez hídrica desponta como um fator limitador do crescimento econômico e do desenvolvimento social, principalmente nas economias mais avançadas da região, o que faz do acesso a este recurso um assunto de importância estratégica em suas agendas políticas (Turton, 2015).

Não obstante os muitos alertas acerca da crescente possibilidade de presenciarmos entreveros envolvendo disputas por água, Gleditsch, Furlong, Hegre, Lacina e Owen (2005) e Bernauer e Boehmelt (2013) ressaltam que da mesma forma como o tema é capaz de suscitar ações conflitivas, em situações de escassez ele apresenta igual potencial para fomentar iniciativas de cooperação e meios alternativos de so-

12. Até pouco tempo citadas na lista das bacias mais ameaçadas do mundo, as estruturas hidrográficas da África Austral não mais estão em risco e uma das razões é, precisamente, porque, ao longo do tempo, instituições foram criadas para lidar com questões relacionadas à solução de conflitos e, neste propósito, elas têm sido bem sucedidas.

13. Exclui-se do Complexo Hidropolítico da África Meridional Madagascar e Ilhas Maurício por sua condição insular. 
lução de controvérsias. Segundo Turton (2003, p. 31), Turton (2015) e Turton et al. (2006, p. 8) esta última tendência prevalece no quadro hidropolítico da África Meridional por duas razões fundamentais.

Em primeiro lugar, há na região um histórico prévio de cooperação em relação aos recursos hídricos, observável mesmo "during the conflict years of Superpower overlay and Apartheid's struggle for regional hegemony" (Turton, 2009, p. 6), o que indica a prevalência de interações pacíficas entre os ribeirinhos e, igualmente, a politização do tema ao se constatar a institucionalização e implementação de normas específicas em uma disposição cronológica durável (Turton, 2015).

Ilustra bem esta situação o tratado celebrado em 1986 entre África do Sul e Lesoto para a implementação do projeto denominado "Lesotho Highlands Water Project" (LHWP). Com o término dos empreendimentos hidráulicos previstos no LHWP para 2020, este acordo - erigido às bases de um audacioso plano cooperativo de engenharia - objetiva, de forma geral, fornecer água e energia à África do Sul e, por outro lado, propiciar maior autonomia energética ao Lesoto em relação a seu único vizinho.

Envolvendo uma ampla rede operacional (represas, túneis, canais, instalações hidrelétricas) o LHWP prevê o represamento e desvio de alguns rios de forma a canalizar parte das águas disponíveis nos altiplanos do Lesoto para uso na agricultura e consumo urbano na África do Sul, atualmente maior empregador de mão de obra do país vizinho e responsável por mais de $20 \%$ de seu PIB. Em contrapartida, o Lesoto recebe da África do Sul um repasse anual de cerca de US\$ 60 milhões em royalties pelo uso dos recursos hídricos transferidos e boa parte da energia hidrelétrica gerada neste processo ratificando, assim, a existência de uma genuína "simbiose hidropolítica" ${ }^{[14]}$ entre os dois ribeirinhos (International Institute for Enviromment and Development [IIED], 2015, p. 2).

Ademais, este caso emblemático é uma demonstração de que "even with power disparity, there is possibility for agreement over water resources through economic benefits" (Wolf \& Newton, 2008, p. 1) ${ }^{[15]} \mathrm{em}$ um contexto em que o êxito dos mecanismos de governança vem deslocando, progressiva e consistentemente, o eixo das relações hidropolíticas na África Meridional do conflito potencial ao potencial de cooperação (Kaniaru, 2015):

14. No jargão da biologia, a simbiose é entendida como uma relação mutuamente vantajosa entre dois ou mais organismos vivos que agem ativamente, em conjunto, para proveito mútuo. No exemplo citado, entre Lesoto e África do Sul, adota-se a aplicação analógica do termo por descrever satisfatoriamente o que seria uma simbiose hidrológica entre aqueles que são os atores por excelência na hidropolítica internacional: os Estados. Note-se, entretanto, que o conceito não foi totalmente desenvolvido no artigo e, por conseguinte, outras considerações são necessárias para refiná-lo. Uma reflexão iminente, por exemplo, diz respeito ao papel dos desequilíbrios de poder, uma vez que as simbioses hidropolíticas devem basear-se em trade-offs consensuais e não impostos. Um bom ponto de partida para a discussão é o trabalho de Mark Zeitoun e Jeroen Warner (2006) sobre "hidro-hegemonia".

15. Há uma grande assimetria na região do SADC. Enquanto a África do Sul responde por $72 \%$ do PIB sub-regional, a segunda maior economia, Angola, gera em torno de 7\%, Moçambique 2\%, Namíbia 1,9\% e o Lesoto apenas $0,4 \%$. 


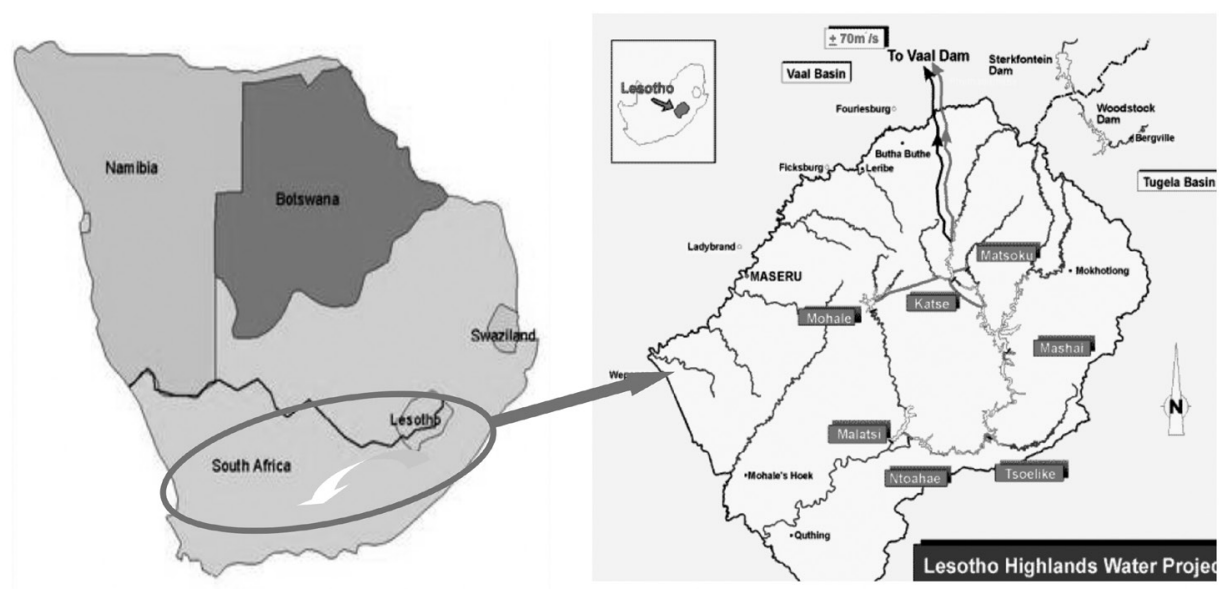

Figura 2. África do Sul e Lesoto: um caso de simbiose hidrológica

Fonte: Elaborado a partir de: <www.lesotho.gov.ls $>$.

Em segundo lugar, os possíveis constrangimentos gerados pela escassez hídrica para o desenvolvimento local, em especial para os principais atores da sub-região, induzem a busca por soluções cooperativas na resolução de problemas ao invés de incentivos ao conflito (Turton, 2015). Essa tendência identificada por Turton há mais de uma década, e atualmente consolidada pelos arranjos cooperativos dela resultantes, deve-se ao fato de os recursos hídricos serem percebidos como:

so important for each riparian state. Too important to fight over, to the extent that water agreements are significant enough to be considered as drivers of international relations in their own right, leading to the conclusion that a Hydropolitical Complex exists in Southern Africa (Turton, 2005, p. 37).

Vê-se, portanto, nesta região, o comportamento dominante moldado pela cooperação e os conflitos que eventualmente surgem sendo resolvidos pacificamente. Por conseguinte, o reconhecimento destas práticas resulta em um jogo de soma positiva (plus-sum outcome) em que os benefícios da cooperação são evidentes, o que, por sua vez, influi diretamente na forma como os ribeirinhos se percebem (Kaniaru, 2015; Queiroz, 2012; Warner, Van Burren \& Edelenbos, 2013).

Cabe destacar que o primeiro protocolo assinado no âmbito da Comunidade para o Desenvolvimento da África Austral (SADC) ${ }^{[16]}$ versa especificamente sobre Sistemas Hidrográficos Compartilhados (Protocol on Shared Watercourses Systems), o que atesta tanto a importância estratégica dos recursos hídricos para o desenvolvi-

16. A Comunidade para o Desenvolvimento da África Austral foi criada em 1992 com o intuito de incrementar as relações comerciais entre os países-membros, promover esforços cooperativos para a manutenção da paz e segurança na região, institucionalizar a utilização sustentável dos recursos naturais e a proteção do meio ambiente, dentre outras disposições. 
mento sub-regional como a institucionalização de regimes cooperativos - na maior parte das vezes sob a forma de Comissões de Bacias Hidrográficas - como opção para a solução de problemas.

Neste esforço, é igualmente válido pontuar a disposição normativa do Tratado institutivo da SADC que, deste logo, obriga as partes a resolverem possíveis disputas de forma amigável, por meio de negociações diretas. O tratado determina, ainda, que no caso deste recurso falhar, as disputas sejam trazidas à apreciação do Tribunal do bloco, criado para garantir "adherence to and the proper interpretation of the provisions of the treaty and the subsidiary instruments, and to adjudicate upon such disputes as may be referred to it" (art.16) reiterando-se que, para tanto, sua jurisdição se estende ao Tratado e todos seus protocolos, inclusive o Revised Protocol on Shared Watercourses, de 2000. ${ }^{[17]}$

Corrobora esta tendência a criação, em setembro de 1994, da Comissão da Bacia do Rio Okavango (OKACOM - Okavango River Basin Commission) entre Namíbia, Angola e Botsuana sob o lema "três países, um rio" com o objetivo de promover, dentre outras disposições, o desenvolvimento coordenado e sustentável dos recursos hídricos compartilhados e do seu meio ambiente e, ao mesmo tempo, tratar das necessidades legítimas de cada um dos Estados ribeirinhos. ${ }^{[18]}$

Esta Comissão, composta por representantes ministeriais ligados à gestão dos recursos hídricos em cada um dos Estados-membros, estabeleceu, subsidiariamente, um fórum de discussão que reúne uma comunidade epistêmica altamente especializada, a Comissão Diretora da Bacia Hidrográfica do Okavango (Okavango Basin Steering Committee - OBSC). Dentre outras atribuições, ela é responsável pela elaboração de uma agenda técnico-científica sobre assuntos ligados à bacia como construção de barragens e desvios, irrigação e poluição e seus potenciais efeitos (Okovango River Besin Comission [OKACOM], 2015).

Complementarmente, um dos maiores desafios a serem enfrentados por estes atores consiste em implementar grandes planos estruturais regionais de transferência de recursos hídricos capazes de lidar com as limitações econômico-sociais impostas por um cenário de escassez hídrica, empreendimento possível somente através da cooperação efetiva entre os envolvidos de forma a viabilizar projetos hidráulicos de grande magnitude, como a reversão de águas entre bacias. ${ }^{[19]}$

17. Apesar de o Tribunal estar formalmente incumbido de mediar disputas entre "States and between natural or legal persons and States" e entre "States and the Community" (art. 17-18 do Protocol on Tribunal and Rules of Procedure), uma resolução adotada durante a Cúpula da SADC, realizada em 2012, restringiu sua atuação exclusivamente às disputas interestatais.

18. Angola, país de montante e, portanto, em uma posição privilegiada do ponto de vista hidropolítico, apresenta necessidade urgente de desenvolvimento, em especial para a reconstrução pós-conflito no sul do país. A Namíbia, país de montante em relação a Botsuana, mas de jusante em relação a Angola, encontra muitas limitações ao seu desenvolvimento, especialmente na região rural nordeste devido ao quadro de escassez que assola a área. Por fim, Botsuana, país que apresenta bons indicadores de desenvolvimento econômico, é o mais vulnerável em termos hídricos por ser um país com relativamente poucos recursos e, também, por estar a jusante em relação aos outros dois ribeirinhos.

19. Dentre estes projetos de grande envergadura destacam-se os planos de extração de águas do Zambeze para os rios Okavango e Cunene, além de uma hidrovia ligando as Bacias do Zambezi e Limpopo. Outro 
Temos, assim, o Complexo Hidropolítico da África Meridional desenvolvendo-se em torno de um eixo principal formado por algumas das economias mais dinâmicas da região: África do Sul, Botsuana, Namíbia e Zimbábue. Concomitantemente, estes são também os países que enfrentam os maiores problemas de estresse hídrico já que se encontram muito próximos de alcançar o limite de exploração dos recursos disponíveis em seus territórios (escassez de primeira ordem), o que pode ser um fator limitador tanto do desenvolvimento social como do crescimento econômico (escassez de segunda ordem).

Estes quatro países, os chamados "pivotal states" ${ }^{[20]}$ encontram-se, em grande medida, interligados por duas das principais bacias hidrográficas da região (pivotal basins), ${ }^{[21]}$ Orange e Limpopo, além de compartilharem outros sete sistemas hidrográficos menores (Pungué, Buzi, Save, Incomati, Umbeluzi, Maputo e Thukela) com os demais co-ripários formando, assim, uma complexa e multifacetada rede de interdependência hidrológica: o Complexo Hidropolítico da África meridional (CHAM):

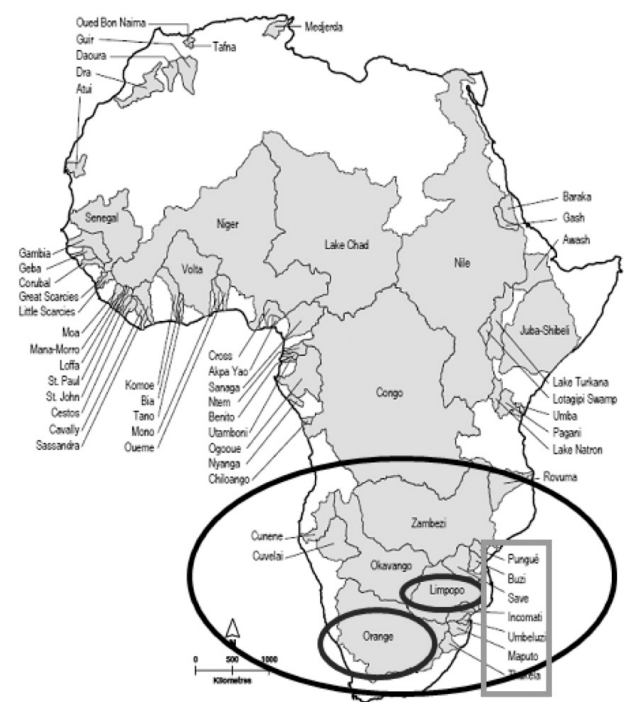

Figura 3. Complexo Hidropolítico da África Meridional (CHAM)

Fonte: Adaptado de Turton (2005, p. 4).

caso emblemático está na proposta feita pela Namíbia, um dos países mais áridos da região, para desviar $1 \%$ do curso do Okavango para Windhoek, a capital, projeto este já rejeitado pelos outros ribeirinhos que nele veem uma séria ameaça à sobrevivência de comunidades ribeirinhas e de atividades econômicas importantes como a agropecuária e o turismo.

20. São aqueles ribeirinhos que apresentam maior grau de desenvolvimento econômico e, igualmente, um alto grau de dependência quanto aos recursos hídricos por eles compartilhado(s) como fonte estratégica de suprimento de água para a manutenção de suas atividades produtivas (Turton, 2005, p. 16).

21. São aquelas bacias que se encontram próximas de seu limite de exploração por serem estrategicamente vitais para o desenvolvimento das atividades econômicas desenvolvidas nos países ribeirinhos, principalmente nos pivotal states. No caso do $\mathrm{CH}$ da África Meridional três bacias encontram-se nesta categoria: Orange, Limpopo e Incomati. 
Tabela 1. Principais Bacias Hidrográficas no CHAM

\begin{tabular}{|c|c|c|c|}
\hline Rio & $\begin{array}{l}\text { Área da Bacia } \\
\qquad\left(\mathrm{km}^{2}\right)\end{array}$ & Estados Ribeirinhos & $\begin{array}{c}\text { Mecanismos de Governança } \\
\text { Existentes }\end{array}$ \\
\hline Buzi & 31.000 & Zimbabwe, Mozambique & - \\
\hline Congo & 3.730 .470 & $\begin{array}{l}\text { Angola, Burundi, Rwanda, } \\
\text { Central African Republic, } \\
\text { Tanzania, Cameroon, DR } \\
\text { Congo, Zambia }\end{array}$ & $\begin{array}{l}\text { Commission Internationale } \\
\text { du Bassin Congo-Oubangui- } \\
\text { Sangha (CICOS) }\end{array}$ \\
\hline Cuvelai & 100.000 & Angola, Namibia & - \\
\hline Incomati & 49.965 & $\begin{array}{l}\text { South Africa, Swaziland, } \\
\text { Mozambique }\end{array}$ & - \\
\hline Kunene & 106.500 & Angola, Namibia & $\begin{array}{l}\text { Permanent Joint Technical } \\
\text { Committee (PJTC) }\end{array}$ \\
\hline Limpopo & 408.000 & $\begin{array}{l}\text { Botswana, South Africa, } \\
\text { Zimbabwe, Mozambique }\end{array}$ & $\begin{array}{l}\text { Limpopo Watercourse } \\
\text { Commission(LIMCOM) }\end{array}$ \\
\hline Maputo-Usutu-Pongola & 32.000 & $\begin{array}{l}\text { South Africa, Swaziland, } \\
\text { Mozambique }\end{array}$ & - \\
\hline Okavango & 530.000 & $\begin{array}{l}\text { Angola, Namibia, } \\
\text { Zimbabwe, Botswana }\end{array}$ & $\begin{array}{l}\text { Permanent Okavango River } \\
\text { Basin Water Commission } \\
\text { (OKACOM) }\end{array}$ \\
\hline Orange-Senqu & 721.000 & $\begin{array}{l}\text { Lesotho, South Africa, } \\
\text { Botswana, Namibia }\end{array}$ & $\begin{array}{l}\text { The Orange-Senqu River } \\
\text { Commission (ORASECOM) }\end{array}$ \\
\hline Pungwe & 32.500 & Zimbabwe, Mozambique & - \\
\hline Ruvuma & 155.500 & $\begin{array}{l}\text { Tanzania, Malawi, } \\
\text { Mozambique }\end{array}$ & - \\
\hline Save/Sabi & 106.420 & Zimbabwe, Mozambique & - \\
\hline Umbeluzi & 5.500 & Swaziland, Mozambique & - \\
\hline Zambezi & 1.390 .000 & $\begin{array}{l}\text { Angola, Namibia, Botswana, } \\
\text { Zimbabwe, Zambia, Malawi, } \\
\text { Tanzania, Mozambique }\end{array}$ & $\begin{array}{l}\text { The Zambezi Watercourse } \\
\text { Commission (ZAMCOM) }\end{array}$ \\
\hline
\end{tabular}

Fonte: SADC (2010) e <http://www.sadc.int/themes/natural-resources/water/> (acesso em 06/01/2017).

Como sugerem o mapa e tabela acima, os doze Estados-Membros continentais da SADC partilham várias bacias hidrográficas, condição que estabelece uma profunda interdependência e que ratifica a cooperação e os esforços conjuntos de coordenação como instrumentos vitais na promoção da estabilidade regional via harmonização de políticas e estratégias para lidar com os desafios da gestão de recursos hídricos transfronteiriços. 


\section{Complexo Hidropolítico de Segurança da Bacia do Rio Jordão (CHSJ)}

A região MENA (Middle East North Africa), assim apresentada por Allan (2001, pp. 242-262), ostenta em sua projeção territorial uma estrutura hidropolítica que contribui para dirimir quaisquer dúvidas residuais quanto à gravidade que podem vir a assumir as disputas envolvendo cursos d' água transfronteiriços em um cenário de escassez e profunda interdependência hidrológica, como é o caso do Oriente Médio. Trata-se do Complexo Hidropolítico de Segurança da Bacia do Jordão (CHSJ) cujos recursos hídricos, superficiais e subterrâneos, constituem a principal fonte de água doce de Israel, Jordânia e dos territórios palestinos da Cisjordânia, além de impactar substancialmente - embora em menor medida em comparação aos atores previamente citados - a Síria e o Líbano. ${ }^{[22]}$

Como veremos adiante, a questão hídrica destaca-se não apenas como lídimo vetor do desenvolvimento econômico e da subsistência humana nesta região "in which water is one of the key issues" (Turton, 2001, p. 8), mas, consequentemente, como um componente fundamental da estrutura física e ideacional do Estado (Messerschmid \& Selby, 2015, p. 258).

Nesse sentido, temos, pois, após a primeira guerra árabe-israelense (1948-49), as latentes tensões regionais acentuando-se ainda mais quando Israel iniciou, em 1952, um projeto que previa o uso das águas do Jordão para a irrigação no deserto do Neguev. Logo em seguida, em 1953, os israelenses começaram a construção do desvio do seu "Sistema Nacional de Água" ao norte do Mar da Galileia, na zona desmilitarizada com a Síria, o que resultou em protestos formais por parte da comunidade internacional e em ações militares ao longo da faixa de fronteira incluindo uma série de ataques das unidades sírias de artilharia às obras do empreendimento.

$\mathrm{Na}$ sequência dos acontecimentos uma resolução da ONU autorizou Israel a retomar as obras, mas o instrumento não surtiu maiores efeitos, pois foi vetado pelos soviéticos. Neste mesmo ano, Gamal Abdel Nasser ascende ao poder no Egito empunhando a bandeira de um ambicioso projeto nacionalista amparado no discurso da unidade linguística e religiosa do mundo árabe (pan-arabismo) contando, inclusive, com o apoio militar de Moscou.

Uma das medidas mais ousadas adotadas por Nasser neste período consistiu no bloqueio do Estreito de Tiran, ponto de ligação entre o Mar Vermelho e o Golfo de Aqaba, onde se encontra o porto israelense de Eilath. Reuniam-se, assim, alguns dos ingredientes que conduziriam à segunda guerra árabe-israelense (Guerra de Suez), deflagrada em 1956. A partir daí, o Oriente Médio assumia a condição de um dos principais teatros de disputas por áreas de influência entre as superpotências no contexto da confrontação bipolar da Guerra Fria: enquanto os EUA avalizavam as ações militares de Israel, a União Soviética, por sua vez, financiava a recuperação e modernização do aparato bélico egípcio e sírio (Bickerton \& Klausner, 2014).

22. O Líbano possui vários rios importantes enquanto a Síria conta com os recursos do Eufrates, Oronte e, em menor escala, do Tigre, minimizando, então, a vulnerabilidade relativa de ambos em relação aos recursos da Bacia do Jordão. 
Ainda neste período, os países integrantes da Bacia do Jordão não conseguiram chegar a nenhum acordo formal que viabilizasse um projeto eficaz de gestão compartilhada de seus recursos hídricos. Assim, em 1953, objetivando dirimir a tensão em torno do assunto e, ao mesmo tempo, incentivar a cooperação regional, o presidente norte-americano, Dwight Eisenhower, contando com o aval da ONU, nomeou o embaixador especial Eric Johnston como encarregado pela negociação de uma proposta técnica de alocação das águas do Jordão e seus afluentes entre Jordânia, Israel, Síria e Líbano.

Conhecido como Johnston United Water Plan ou, simplesmente, Plano Johnston, esta proposta recebeu em outubro de 1955 o apoio formal do Comitê Técnico da Liga Árabe, mas, ainda assim, não conseguiu ser aprovado no âmbito da Organização devido ao temor dos países árabes de que "their agreement would imply indirect recognition [...] of Israel" (Shuval, 2000, p. 44). Isso porque uma proposta cooperativa desta magnitude exigiria, por conseguinte, que a Liga Árabe reconhecesse Israel como um Estado legítimo e um usuário, de fato e direito, dos escassos recursos hídricos regionais. Essa postura reacionária gerou junto às autoridades israelenses uma intensa insatisfação e, concomitantemente, uma percepção de insegurança que produziu reflexos diretos na elaboração da doutrina de segurança do país (Abukhater, 2013; Turton, 2003, p. 43).

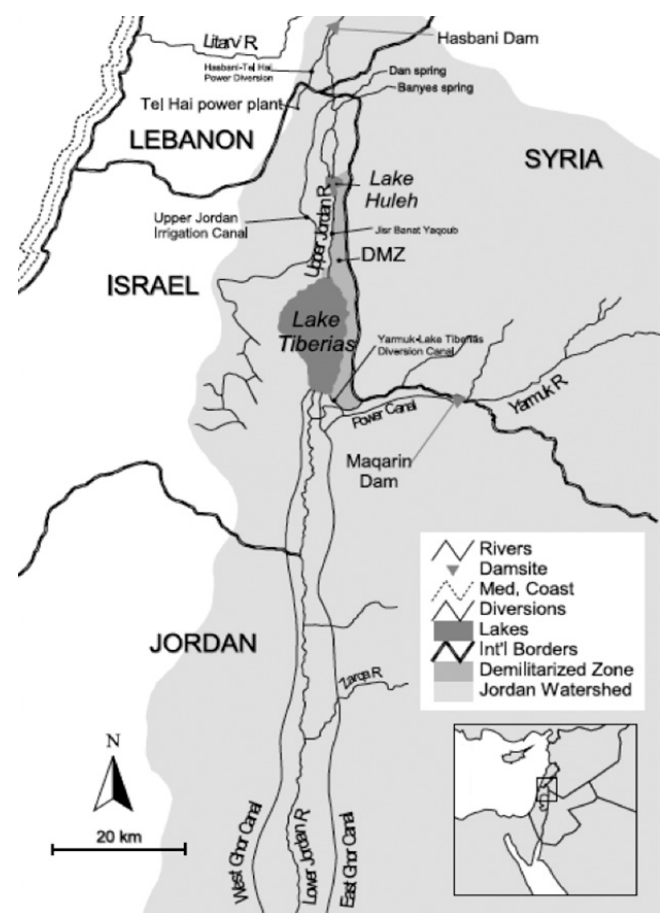

Figura 4. Plano Johnston

Fonte: Elmusa (1998, p. 301). 
Não obstante os citados entreveros, para Wolf (1995, pp. 173-180) o período compreendido entre 1964-1967 foi aquele que evidenciou com maior clareza a existência de uma correlação entre o conflito árabe-israelense e a dimensão hidropolítica. Foi neste contexto, por exemplo, que se iniciou, por uma decisão pan-árabe, o projeto de transferência das cabeceiras do rio Jordão de modo a inviabilizar o transporte de água para Israel através de um dos seus mais audaciosos projetos hidráulicos: o Emissário Nacional de Água, iniciado em 1955 após a rejeição formal da proposta de alocação hídrica sugerida no Plano Johnston. ${ }^{[23]}$

Em resposta, os israelenses empreenderam uma intensa ofensiva militar aérea e terrestre culminando, exitosamente, na interrupção das obras do desvio, mas, igualmente, em uma série de contramedidas capitaneadas pelo Egito. A crescente tensão que marcou o citado recorte temporal inevitavelmente levou estes atores ao terceiro conflito árabe-israelense - a Guerra dos Seis Dias (junho/1967) - que foi, em parte, a resposta de Israel à proposta jordaniana e síria de desviar o rio Jordão para uso próprio (Clarke \& King, 2005, p. 79). Nesta mesma direção, Lindholm (1995, p. 70) argumenta que se a água não foi a principal causa da deflagração do conflito, certamente foi uma das forças motrizes que contribuiu para exacerbar a escalada de agressões entre árabes e israelenses em 1967.

Essa percepção transparece claramente na declaração dada por Ariel Sharon quando afirmou, ainda enquanto Chefe do Estado Maior do Comando Norte do Exército de Israel, que: "people generally regard 05 June 1967 as the day the Six-Day War began. But in reality the Six-Day War started two and a half years earlier, on the day Israel decided to act against the diversion (initiated by upstream Arab States) of the Jordan" (Turton, 2003, p. 49). Como resultado, o desenlace das hostilidades culminou em uma esmagadora vitória israelense e, por conseguinte, em um novo arranjo geográfico que ampliou as fronteiras do país e, concomitantemente, o acesso aos recursos hídricos da região em quase 50\%.

Esta visível centralidade da água no contexto geopolítico do Oriente Médio pôde ser mais uma vez constatada no teor do discurso proferido por outra emblemática autoridade israelense. Em 1973, David Ben-Gurion, um dos idealizadores da criação do Estado de Israel e primeiro-ministro do país de 1948 a 1953 e de 1955 a 1963, afirmou que "it's necessary that the water sources, upon which the future of the Land depends, should not be outside the borders of the future Jewish homeland [...] the Land needs this water" (Lindholm, 1995, p. 61).

Dessa forma, a ocupação do planalto de Golã e, especialmente, dos territórios da Cisjordânia, de onde vêm $40 \%$ da água doce de Israel, deu-lhe acesso não apenas às águas das nascentes do Jordão, mas também o controle de $20 \%$ da margem norte do Yarmuk - seu principal afluente - a margem oriental do lago Tiberíades, o Banias e o aquífero da Cisjordânia, fundamental para o país a ponto de o ex-ministro da

23. O Emissário Nacional de Água de Israel (National Water Carrier), concluído em 1964, consiste em uma ampla estrutura integrada de canais, dutos e tubulações responsável pela transposição de mais de 400 milhões de m3 de água/ano da região centro-norte até as partes mais áridas do país, no litoral sul. 
economia israelense, Rafael Eitan, afirmar, em 1990, que "a perda da Cisjordânia significaria a de Israel" (Le Prestre, 2000, p. 446).

Em relação às colinas de Golã, cabe ressaltar que sua ocupação garante a Israel 770 milhões de m3/ano, o que corresponde a cerca de $1 / 3$ de seu consumo anual (Caubet, 2006, p. 30). Portanto, os fatos e dados apresentados denotam claramente que uma hipotética retirada israelense ocasionaria profundos rearranjos na geopolítica do Oriente Médio, inclusive em termos hidropolíticos, pois daria à Síria a privilegiada condição de se tornar novamente um Estado a montante do Jordão alterando, sobremodo, o jogo de poder regional (Tignino, 2010).

O status da água na condição de tema de segurança nas relações siro-israelenses transparece nitidamente em declarações como a proferida por Gadi Baltianski, porta-voz do ex-premiê Ehud Barak, quando, por ocasião da retomada das negociações de paz entre os dois países, disse que: “antes da guerra de 1967 tínhamos problemas, pois a Síria desviava as fontes d'água de Golã, e o primeiro-ministro [Barak] estima que devemos nos certificar de que isto não mais acontecerá" (Caubet, 2006, p. 30; Chesnot, 1991, p. 4).

Quanto ao acesso à água por parte dos palestinos na Cisjordânia - território oportunamente rotulado por Wolf (1996) apud Allan (2001, pp. 39-40) de "hidroestratégico" - os fatos concretos mostram uma realidade nada favorável. Devido ao aumento no número de colonos judeus nos territórios ocupados, a pressão sobre os recursos hídricos e a desigualdade em sua distribuição aumentaram consideravelmente (Tignino, 2014).

O consumo médio diário de água dos palestinos na Cisjordânia é de 71 litros per capita enquanto o consumo israelense supera os 300 litros, muito superior à quantidade mínima diária recomendada pela Organização Mundial da Saúde (OMS) de 100 litros per capita (Carvalho, 2013). Em termos quantitativos, estes dados indicam que os palestinos utilizam uma quantia estimada entre $125-130 \mathrm{~mm}^{3}$ /ano (milhões de metros cúbicos/ano), contra $233 \mathrm{~mm}^{3}$ /ano na Jordânia e $424 \mathrm{~mm}^{3} /$ ano em Israel.

Estas condições demonstram que a escassez hídrica tornou-se, sobretudo para a comunidade palestina, um grande entrave ao adequado suprimento de suas necessidades mais rudimentares, quadro este ocasionado, em grande medida, pelo sistema de alocação de água vigente desde a ocupação militar israelense de 1967 que, como dito, destinou-lhe pouco mais de 15\% dos recursos hídricos disponíveis (The Islaeli Information Center for Human Rights in the Occupied Territories [B'TSELEM], 2016; Hass, 2014; United Nations, 2015; Zeitoun \& Warner, 2006).

É o caso, por exemplo, da Ordem Militar n. 158, expedida logo após a Guerra dos Seis Dias, estabelecendo o controle total de Israel sobre os aquíferos da Cisjordânia. Esta lei determinou, dentre outras disposições, que os poços artesianos palestinos não poderiam exceder $140 \mathrm{~m}$ de profundidade, enquanto aos judeus era permitida a perfuração de poços com mais de 800m (Lindholm, 1995, p. 80; Palestinian Water Authority, 2013).

Diz ainda Le Prestre (2000, p. 446) que desde 1967 nenhum palestino foi autorizado a perfurar um novo poço para agricultura, tampouco reparar um poço existente nas proximidades de um poço israelense. Agrava este cenário o fato de mais de 
2/3 dos lençóis subterrâneos da Cisjordânia apresentarem um alto grau de vulnerabilidade hidrogeológica capaz de comprometer sua capacidade de armazenamento hídrico devido à exploração excessiva e poluição atestando, pois, que a escassez na região não é apenas um problema quantitativo (UN Economic and Social Comission for West Asia [ESCWA], 2013).

Aponta Handcock (2004, p. 5) que a gravidade da situação aguçou nas autoridades israelenses a percepção já prevalecente de que a criação de um Estado palestino na Cisjordânia poderia comprometer seriamente a segurança hídrica do país. Um dos argumentos suscitados para justificar tal temor sustentava que uma excessiva perfuração para a construção de poços na Cisjordânia por parte dos palestinos poderia causar problemas irreversíveis de salinização em todo o sistema hídrico israelense fazendo da questão, nas palavras de Shapira (1978) apud Ohlsson (1995, p. 66) "casus belli for Israel, because, in contrast to the situation elsewhere, no substitutes can be offered to Israel in this matter".

Segundo Tignino (2014, p. 395) e (Messerschmid \& Selby, 2015) estes fatos fornecem evidências robustas que comprovam a existência de uma política sistemática de captação de recursos e de indução de escassez que vem sendo utilizada como um instrumento eficiente para a garantia da hegemonia política e econômica de Israel na Cisjordânia. Em uma perspectiva temporal mais recente, a situação no Oriente Médio, incluindo sua dimensão hidropolítica, ganhou novos rumos, ou pelo menos expectativas de resultados positivos, com a celebração dos paradigmáticos Acordos de Oslo na década de 1990.

Em setembro de 1993, Yitzhak Rabin (1922-1995), então primeiro-ministro de Israel, e Yasser Arafat (1929-2004), líder palestino, assinavam nos jardins da casa Branca, em Washington, o Acordo de Oslo I. O referido Acordo estabeleceu a autonomia das comunidades palestinas residentes em Jericó, na Cisjordânia e na Faixa de Gaza, territórios a oeste do rio Jordão ocupados durante a Guerra dos Seis Dias e que passavam ao controle da Autoridade Palestina (AP), presidida por Arafat.

Além disso, o Acordo de Oslo I ratificou a percepção de que um projeto de uma paz substancial entre israelenses e palestinos passava, inegavelmente, pela questão da água. Por isso, o acordo previa a criação de um Programa de Desenvolvimento Hídrico Comum, formado por uma agência de bacia hidrográfica e um comitê de cooperação que, juntos, deveriam formular propostas que viabilizassem tanto o acesso à água como sua divisão equitativa.

Entretanto, a ausência de compromissos concretos, a natureza ambígua dos mecanismos legais existentes quanto à distribuição e exploração dos recursos hídricos e a recusa intransigente de Israel em reconhecer um plano de partilha equitativa constituíram grandes empecilhos para o avanço das negociações (Carvalho, 2013; Clarke \& King, 2005, p. 79; Handcock, 2004, p. 3; Le Prestre, 2000, p. 447; Messerschmid \& Selby, 2015; Tignino, 2014).

O quadro descrito aponta para o fato de que em um contexto de escassez e interdependência hidrológica, os Estados que controlam cursos d'água ou se apropriam deles por dispor de recursos militares muito superiores, como é o caso de Israel, normalmente não estão dispostos a negociar. Tampouco encontram incentivos óbvios 
para a cooperação com aqueles Estados incapazes de negociar em condições paritárias estando estes últimos, por isso, em uma situação de vulnerabilidade e dependência em relação às decisões do(s) ribeirinho(s) mais proeminente(s).

Assim, considerando tal cenário, entende Le Prestre (2000, p. 446) que aos Estados ribeirinhos quedam-lhes três opções principais nesta situação: 1) assinar acordos de cooperação, o que é difícil, mas não impossível; 2) reestruturar suas economias de forma a torná-las menos dependentes dos recursos hídricos compartilhados, tarefa que também impõe muitas dificuldades e; 3) militarizar as disputas pela água, desde que tenham os recursos e incentivos necessários. Diante destas opções, não foi difícil constatar que o problema da água seguiria sendo um entrave no andamento das negociações subsequentes sobre a autonomia palestina na Cisjordânia, como demonstram os fatos históricos doravante apresentados.

O acordo provisório posterior, conhecido como Oslo II (setembro de 1995), dividiu a Cisjordânia em três zonas diferenciadas: a Zona “A”, de população predominantemente palestina, compreendendo as seis maiores cidades da região sob jurisdição da Autoridade Palestina (Jenin, Naplouse, Rammallah, Tulkaren, Belém e Kalkiya), à exceção de Hebron, parcialmente sob o controle de Israel. A Zona "B", composta pela quase totalidade das vilas palestinas, encontra-se sob a autoridade conjunta de palestinos e israelenses.

Por fim, a Zona "C", onde vive cerca de $60 \%$ da população palestina, está sob jurisdição exclusiva de Israel e ocupa aproximadamente $70 \%$ da Cisjordânia, incluindo todo o vale do Jordão garantindo, assim, aos israelenses, a manutenção do controle dos suprimentos de água desta região, mesmo diante de seu reconhecimento expresso quanto aos direitos palestinos de acesso à água, conforme disposto no art. 40, Apêndice B, do acordo de Oslo II (Caubet, 2006, p. 26). Como resultado deste quadro, em recente relatório a ONU aponta que:

Before the occupation, agriculture was the main source of labour and resources for Palestinians. Palestinian agriculture has, however, been adversely affected by measures taken by Israel as the occupying Power, in particular land seizures and restrictions on access to land and water resources (A/68/513, para. 40). From 1965 to 1994, cultivated areas shrank by 30 per cent from 1965 to 1994, and Palestinian agricultural production was reduced, from 50 per cent in 1968 to 4.9 per cent of GDP in 2013 (United Nations, 2015, p. 10).

Portanto, enquanto os palestinos, com base em questões humanitárias e de soberania, reivindicam maior parcela dos recursos hídricos da Cisjordânia, Israel, por sua vez, se opõe ao princípio da utilização equitativa não admitindo, desta maneira, qualquer tipo de revisão da alocação atual alegando, para tal, direitos históricos e sua estreita dependência econômica da água (B’TSELEM, 2016; Tignino, 2010, p. 669; United Nations, 2015). ${ }^{[24]}$

24. Cabe lembrar que pelo menos uma dúzia de violações do cessar-fogo, entre 1951 e 1967, teve como causa a disputa pelas fontes de água doce da região. Daí as rivalidades políticas e territoriais entre palestinos, israelenses, jordanianos, sírios e libaneses estarem intimamente ligadas à afirmação da soberania sobre estes recursos. 


\section{Conclusão}

A água, por tudo o que foi dito, é muitas vezes apresentada como tema protagonista das mais dramáticas predições por figurar, dentre alguns dos motivos suscitados, como recurso escasso e indispensável à manutenção da vida e ao exercício de diversas atividades cotidianas, porém vitais. Assim, frequentemente é tratada como fonte de poder e, consequentemente, assunto de segurança.

Contudo, ainda que muitas das admoestações apresentadas com relação ao tema sejam pertinentes, Le Prestre (2000, pp. 427-428) nos alerta acerca do perigo de incorrer-se em reducionismos. Isso porque, nas situações em que os usos da água são objetos de disputa, será sempre possível construir um laço direto ou indireto, próximo ou longínquo, entre o quadro de instabilidade que se pretende explicar e uma variável hidropolítica e, assim, ver como resultado dessa perigosa associação, o anúncio de instabilidades futuras.

Em outras palavras, o que Le Prestre sugere é cautela ao lidar com o binômio água-segurança, demonstrando haver a necessidade de se dimensionar a real influência dos recursos hídricos diante da multiplicidade de variáveis outras que também apresentam potencial para agravar uma situação de instabilidade. Dessa forma, torna-se mais útil, e viável, estudar a hidropolítica como um elemento gerador de tensões suplementares. Afinal, é difícil provar que a água seja a variável desencadeara de um conflito, pois, geralmente, são múltiplas as causas que lhe dão origem sendo, portanto, ilusório querer isolar um fator.

E para determinar o papel da água nesta complexa equação, as evidências empíricas constituem um importante instrumento. Observada a aplicação do referencial teórico em dois casos em que a água e seus múltiplos usos se destacam como uma importante variável nas dinâmicas regionais foi possível ter-se uma compreensão geral das interações hidropolíticas que surgem entre aqueles atores que compartilham as águas de um determinado sistema hidrográfico e, por conseguinte, suas implicações para a eficiente governança destes recursos comunais.

Assim, a aplicação do método comparado à estrutura conceitual dos Complexos Hidropolíticos/Complexos Hidropolíticos de Segurança permitiu-nos observar que, em geral, a propensão à cooperação prevalece nas situações em que as identidades entre os atores são percebidas como positivas, caso em que se enquadra o $\mathrm{CH}$ da África Meridional. Por outro lado, sobressai o balanceamento de poder, por vezes com o uso de meios extraordinários, como a força, nos casos em que essas identidades são vistas como negativas e/ou os mecanismos de governança existentes não conseguem dirimir as percepções prevalecentes de ameaça, situação observável no CHS da Bacia do Jordão.

Quanto às peculiaridades de nosso universo de análise, o contraste de contextos nos levou a inferir que no Complexo Hidropolítico da África Meridional disputas por recursos hídricos têm sido mitigadas por meio de arranjos institucionais capazes de minimizar o potencial de conflito ao proporcionar a institucionalização de mecanismos de governança via iniciativas como a criação de comitês gestores intergovernamentais. Como resultado, ainda que em um cenário prevalecente de escassez de primeira ordem (ou de recursos naturais) marcado por disputas em torno de 
recursos hídricos, as questões hidropolíticas vêm sendo satisfatoriamente mantidas no nível dos processos usuais de barganha e disputa da esfera política, ou seja, como uma questão majoritariamente técnica.

A partir daí temos a síntese da rationale que define este $\mathrm{CH}$. Amparada nos vínculos simbióticos estabelecidos entre os elementos que integram tal estrutura, ela é, em linhas gerais, a resultante de um notável grau de interdependência hidrológica que inevitavelmente os conecta em um enredo multissetorial altamente politizado, efeito de um contexto prevalecente de cooperação impulsionado, sobremaneira, pela percepção de ganhos mútuos (plus-sum outcome).

Por sua vez, ao olharmos para a hidropolítica no CHS da Bacia do Jordão vimos que a intensificação das tensões em torno da água não é ocasionada apenas por problemas relacionados à escassez de primeira ordem. Como visto, ela envolve outras questões complexas e multidimensionais. Neste caso, os conflitos analisados referem-se, fundamentalmente, a problemas de integridade física/territorial e de identidade demonstrando, pois, que as estruturas físicas e ideacionais do Estado figuram como os principais domínios em que as percepções em termos de ameaças tomam forma.

Os fatos narrados igualmente apontam a água como um elemento adicional de risco, um fator suplementar na definição da agenda regional de segurança e no processo de construção de percepções identitárias entre os atores regionais. Nesse sentido, foi possível constatar que as disputas pelo controle dos recursos hídricos tem sido relevantes na manutenção de um quadro de tensão capaz de desencadear crises ou dificultar a solução daquelas já existentes em um crítico contexto de escassez de segunda ordem (onde prevalece a falta de disposição/habilidade para lidar com os desafios impostos por um quadro de escassez física e/ou distribuição desigual dos recursos hídricos) em que sobressaem relações de inimizade e em que são poucos efetivos os instrumentos de governança.

Logo, seja em um continuum de conflito ou cooperação, ${ }^{[25]}$ a acomodação satisfatória dos interesses concorrentes dos Estados ribeirinhos é um dos grandes desafios com os quais se deparam os mecanismos de governança evidenciando, pois, o potencial que tem a interdependência hidrológica para afetar a estabilidade política regional, sobretudo, em cenários de escassez.

Por isso, este esforço em ordenar demandas e preferências aparentemente incompatíveis exige, para uma maior eficácia das ações pretendidas, a adoção de abordagens policêntricas e descentralizadas (ou seja, em vários níveis, com a ativa participação de atores locais, nacionais e regionais), de forma a dotar os instrumentos de gestão compartilhada de maior capacidade de inclusão, flexibilidade e adaptabilidade às incertezas e complexidades que, não raras as vezes, surgem em tais circunstâncias.

25. Para uma análise complementar sobre as dinâmicas oriundas do binômio "conflito-cooperação" em torno de recursos hídricos compartilhados ver o trabalho de Queiroz (2012) sobre a Bacia do Prata. 


\section{Agradecimentos}

Os autores são imensamente gratos aos professores Aaron T. Wolf (Oregon State University), Andrea K. Gerlak (University of Arizona) e Michael T. Klare (Hampshire College) por seus comentários e sugestões à versão prévia deste texto.

\section{Referências}

Abukhater, A. (2013). Water as a catalyst for peace: Transboundary water management and conflict resolution. New York: Routledge.

Allan, J.A. (2001). The Middle East water question: Hydropolitics and the global economy. London: I. B. Tauris \& Co.

Allan, T. (2002). Water resources in semi-arid regions: real deficits and economically invisible and politically silent solutions. In A. R. Turton \& E. Henwood (Eds.) Hydropolitics in the developing world: A southern African perspective (pp. 23-36). Pretoria: African Water Issues Research Unit (AWIRU).

Bernauer, T. \& Boehmelt, T. (in press). Basins at Risk - Predicting international river Basin conflict and cooperation. Global environmental politics. Available at $<\mathrm{http}: / /$ papers. ssrn.com/sol3/papers.cfm?abstract_id=2365782> (acesso em jan. 2016).

B'TSELEM (2016). Israel cut back on the already inadequate water supply to Palestinians. The Israeli Information Center for Human Rights in the Occupied Territories. Available at <http://www.btselem.org/water/201609_israel_cut_back_supply>.

Bickerton, I. J. \& Klausner, C. L. (2014). A History of the Arab-Israeli conflict. New Jersey: Pearson Education, Limited.

Buzan, B., Wæver, O. \& De Wilde, J. (1998). Security: a new framework for analysis. Boulder and London: Lynne Rienner Publishers.

Carvalho, T. L. (2013). A disponibilidade dos recursos hídricos no contexto do conflito entre Palestina e Israel. Conjuntura Internacional. Available at $<$ https://pucminasconjuntura.wordpress.com/2013/06/24/a-disponibilidade-dos-recursos-hidricos-no-contexto-do-conflito-entre-palestina-e-israel/>.

Castro, J. E. (2007). Water governance in the twentieth-first century. Ambiente e Sociedade, 10(2), 97-118.

Caubet, C. G. (2006). A Água Doce nas Relações Internacionais. São Paulo: Manole.

Clarke, R. \& King, J. (2005). O atlas da água. São Paulo: Publifolha.

Elhance, A. P. (1999). Hydropolitics in the third world: conflict and cooperation in international rivers. Washington: US Institute of Peace.

Elmusa, S. (1998). Toward a unified management regime in the Jordan Basin: The Johnston Plan revisited. Transformations of Middle Eastern Natural Environments: Legacies and Lessons, 103, 297-313.

ESCWA \& BGR (UN Economic and Social Commission for West Asia; Bundesanstalt für Geowissenschaften und Rohstoffe). (2013). Inventory of shared water resources in Western Asia. New York: United Nations. Available at <www.escwa.un.org/information/ pubaction.asp?PubID=1362> (accessed: 2 April 2015). 
Gleditsch, N.P., Furlong, K., Hegre, H., Lacina, B. \& Owen, T. (2006). Conflicts over shared rivers: Resource wars or fuzzy boundaries? Political Geography, 25(4), 361-382.

Handcock, A. (2004).Water Conflict: A critical analysis of the role of water in the Middle East. Available at $<$ http://www.amcips.org/PDF_books/BookIV19.pdf $>$.

Heyns, P. (2002). Interbasin transfer of water between SADC countries: A Development challenge for the future. In A.R. Turton \& R. Henwood (Eds.) Hydropolitics in the developing world: a southern african perspective. Pretoria: African Water Issues Research Unit (AWIRU).

IIED (International Institute for Environment and Development). (2015). Routing revenue from hydropower dams to deliver local development. IIED Briefing.

Jaiantilal, D. (2007). A área de comércio livre na SADC e o Desenvolvimento em Moçambique, com referência ao caso da Agricultura: A carroça em frente aos bois? Paper presented at Conferência de Comemoração dos 10 Anos da Lei de Terras, Maputo.

Kaniaru, W. (2010). A critical assessment of hydropolitics in southern africa: water as a potential factor for conflict and a challenge for co-operation in Southern Africa. Lambert Academic Publishing.

Kaniaru, W. (2015). From scarcity to security: Water as a potential factor for conflict and cooperation in Southern Africa. South African Journal of International Affairs, 22(3), 380-396.

Keohane, R. \& Nye, J. (1989). Power and interdependence (2 ${ }^{\text {nd }}$ ed.). New York: Harper Collins Publishers.

Le Prestre, P. (2000). Ecopolítica Internacional. São Paulo: Senac.

Lindholm, H. (1995). Water and the Arab-Israeli conflict. In L. Ohlsson (Ed.), Hydropolitics: Conflicts over water as a development constraint. London: Zed Books.

Magnoli, D. (1996). O mundo contemporâneo: Relações Internacionais 1945-2000. São Paulo: Moderna.

Marton, P. \& Szálkai, K. (2017). Against the current: deconstructing the upstream/downstream binary in hydropolitical security complexes. New Perspectives: Interdisciplinary Journal of Central \& East European Politics and International Relations, 25(3), $1-27$.

Messerschmid, C. \& Selby, J. (2015). Misrepresenting the Jordan River basin. Water Alternatives, 8(2), 258-279.

Ohlsson, L. (1995). Introduction: The role of water and the origins of conflict. In L. Ohlsson (Ed.), Hydropolitics: Conflicts over water as a development constraint. London: Zed Books.

OKACOM (Okavango River Basin Water Commission) (2015). The Okavango River Basin Steering Committee (OBSC). OKACOM The Permanent Okarango River Basin Water Comission. Available at <http://www.okacom.org/okacom-commission/obsc > (acesso em Junho 2015).

Palestinian Water Authority. (2013). Status report of water resources in the occupied state of Palestine - 2012. Ramallah: State of Palestine. 
Plummer, R., Crona, B., Armitage, D. R., Olsson, P., Tengo, M. \& Yudina, O. (2012). Adaptive co-management: a systematic review and analysis. Ecology and Society, 17(3).

Queiroz, F. A. (2012). Hidropolítica e segurança: as Bacias Platina e Amazônica em perspectiva comparada. Brasília: MRE/FUNAG. Available at <http://funag.gov.br/loja/download/932-HidropolItica_e_Seguranca.pdf>.

Queiroz, F. A. (2012). A hidropolítica platina no contexto do complexo regional de segurança da América do Sul: entre o conflito e a cooperação (1960-1979). Contexto Internacional, 34, 573-616.

Schulz, M. (1995). Turkey, Syria and Iraq: A hydropolitical security complex. In L. Ohlsson (Ed.), Hydropolitics: Conflicts over water as a development constraint. London: Zed Books.

Skocpol, T. \& Somers, M. (1980). The use of comparative history in macro-social inquiry. Comparative Studies in Society and History, 22, 174-197.

Shuval, H. I. (2000). The water issues on the Jordan River Basin between Israel, Syria and Lebanon can be a motivation for peace and regional cooperation. In Green Cross International (Ed.), Water for peace in the Middle East and Southern Africa (pp. 39-55). Geneva: Green Cross International.

Tignino, M. (2010). Water, international peace and security. International Review of the Red Cross, 92(879), 647-74.

Tignino, M. (2014). The right to water and sanitation in post-conflict legal mechanisms: an emerging regime? In E. Weinthal, J. Troell \& M. Nakayama (Eds.), Water and post-conflict peace building (pp. 383-402). New York: Earthscan.

Turton, A. R. (2001). Hydropolitics and security complex theory: an african perspective. Paper presented at the $4^{\text {th }}$ Pan-European International Relations Conference, University of Kent, Canterbury (UK). Available at <http://www.up.ac.za/academic/libarts/polsci/ awiru>.

Turton, A. R. (2002). River Basin commissions in Southern Africa. Paper presented at the World Summit on Sustainable Development, Johannesburg.

Turton, A. R. (2003). The political aspects of institutional developments in the water sector: South Africa and its international river basins (Doctoral Thesis). Faculty of Humanities, University of Pretoria, Pretoria, South Africa.

Turton, A. R. (2005). A Critical assessment of the basins at risk in the Southern African hydropolitical complex. Paper presented at the Workshop on the Management of International Rivers and Lakes hosted by the Third World Centre for Water Management and Helsinki University of Technology, Finland.

Turton, A. R. (2006). Hydro-Hegemony and hydropolitical complex theory. Paper presented at the Second Hydro-Hegemony Workshop, London.

Turton, A. R. (2008). A South African perspective on a possible benefit-sharing approach for transboundary waters in the SADC region. Water Alternatives, 1(2), 180-200.

Turton, A. R. (2009). A Hydropolitical complex as a factor in the international relations of contemporary Southern Africa. (Cambridge Paper). Centre for International Political Studies (CIPS)/ African Water Issues Research Unit (AWIRU): University of Pretoria. 
Turton, A. R. (2015). Hydropolitics and transboundary river basin management: nuances in the Southern African development community. In J. Grant, W. Compaoré \& M. Mitchell (Eds.), New approaches to the governance of natural resources (pp. 224-244). London: Palgrave Macmillan UK.

Turton, A. R., Patrick, M. J. \& Julien, F. (2006). Transboundary water resources in Southern Africa: Conflict or cooperation? Society for International Development, 49(3), 22-31. Available at www.sidint.org/development

UNESCO - United Nations Educational, Scientific and Cultural Organization. (2003). Water for people, water for life: UN World Water Development Report. Paris.

UNESCO - United Nations Educational, Scientific and Cultural Organization. (2015). Relatório Mundial das Nações Unidas sobre o Desenvolvimento de Recursos Hídricos - Água para um mundo sustentável. Brasília. Available at <http://www.unesco.org/ new/fileadmin/MULTIMEDIA/HQ/SC/images/WWDR2015ExecutiveSummary_ POR_web.pdf $>$.

UNITAR - United Nations Institute for Trainingand Research. (2015). The Evolution of the International Regimen of Transboundary Water Resources. UNITAR.

United Nations. (2015). Israeli settlements in the Occupied Palestinian Territory, including East Jerusalem, and in the Occupied Syrian Golan. (Report of the Secretary-General A/HRC/28/44). Office of the United Nations High Commissioner for Human Rights (OHCHR) Available at <http://www.ohchr.org/EN/HRBodies/HRC/RegularSessions/Session28/Documents/A_HRC_28_44_en.doc> (acesso em Setembro, 2015).

Van Buuren, A. (2013). Knowledge for water governance: trends, limits, and challenges. International Journal of Water Governance, 1, 157-175. DOI: 10.7564/12-IJWG6.

Warner, J., Van Buuren, A. \& Edelenbos, J. (2013). Making space for the river: governance experiences with multifunctional river flood management in the US and Europe. London: IWA Publishing.

Wolf, A. T.; Yoffe, S. B. \& Giordano, M. (2003). International waters: Identifying basins at risk. Water Policy, 5(1), 29-60.

Wolf, A. T. (1995). Hydropolitics along the Jordan River: Scarce water and its impact on the Arab-Israeli conflict. Tokyo: The United Nations University Press.

Wolf, A. T., \& Joshua T. N. (2008). Case studies of transboundary dispute resolution: the Lesotho Highlands Water Project. In J. D. Priscolli \& A. T. Wolf (Eds.), Managing and transforming water conflicts. Cambridge: Cambridge University Press.

Zeitoun, M. \& Warner, J. (2006). Hydro-hegemony - a framework for analysis of trans-boundary water conflicts. Water Policy, 8, 435-460. 


\section{Sobre os autores}

FÁBIO Albergaria DE QUEIROZ (PhD) é bolseiro de pesquisa CAPES (Coordenação Brasileira de Aperfeiçoamento de Pessoal de Nível Superior) no Instituto de Relações Internacionais da Universidade de Brasília / Brasil (IREL / UnB) e doutor em Relações Internacionais pelo IREL / UnB. Sua pesquisa de doutorado em segurança hídrica nas Bacias Platina e Amazónica foi contemplada com o Prémio CAPES 2012 como a melhor tese brasileira na área de Relações Internacionais/Ciência Política (fabioaq@hotmail.com).

james augusto pires tiburcio (PhD) é pesquisador visitante de Pós-Doutorado na Universidade Azim Premji / Índia, possui mestrado em Relações Internacionais pelo Instituto de Relações Internacionais da Universidade de Brasília/Brasil (IREL / UnB) e doutorado em Desenvolvimento Sustentável pelo Centro de Desenvolvimento Sustentável da Universidade de Brasília (CDS / UnB).

\footnotetext{
About the authors

FÁBIO ALBERGARIA DE QUEIROZ is a Research fellow at CAPES (Brazilian Coordination for the Improvement of Higher Level Personnel) at the Institute of International Relations of the University of Brasilia / Brazil (IREL / UnB) and holds a doctorate in International Relations from IREL / UnB. His PhD research on water security at La Plata and Amazon Basins was awarded with the 2012 CAPES Prize as the best Brazilian thesis on the field of International Relations/Political Science (fabioaq@hotmail.com).
}

james augusto pires tiburcio is a visiting Post Doctoral Researcher at Azim Premji University/India. He holds a master's degree in International Relations from the Institute of International Relations of the University of Brasilia/Brazil (IREL / UnB) and a doctorate in Sustainable Development from the Center of Sustainable Development at the University of Brasilia (CDS / UnB). 